\title{
The Accounting System of Central State Administrations
}

\author{
Francesco Cancellaro ${ }^{1}$ \\ ${ }^{1}$ Ministry of Economy and Finance - Department for National General \\ Accounting (RGS), Italy, francesco.cancellaro@tesoro.it
}

\begin{abstract}
The many important innovations and reforms that over the years have involved Public Administration in a change and growth process have resulted in the dissemination of new analytical technologies aimed at exploring cost structures and the correlations between costs and achieved results, so as to support Government decision-makers with dependable and verified data.

The achievement of this goal has been facilitated by the legislation introduced in this area over the years and by ICT's continued evolution.

More specifically, IT evolution has brought about the use and dissemination of information systems related to the State Budget and the management of the public expenditure of central State administrations through the standardization not only of its criteria, but also of the tools employed, ensuring an efficient and timely execution of operations.

The Ministry of the Economy and Finance (MEF) and the State General Accounting Department (RGS) are today a crucial pivot of a complete system that supports central State Administrations in the implementation of all their accounting, economic and financial activities and that is going through further evolution, both in the use of new technologies and in the extension of the functional reach of correlated processes.
\end{abstract}

Keywords: information technology mandate, digital signature, substitutive conservation system

\section{The situation prior to the introduction of the information technology mandate}

General State Accounting (RGS) was born as a set of technical and auditing criteria regulating State Budget management operations. Gradually, these accounting operations have been inserted into the legislative system, thus creating a homogenous body of regulations. 
More specifically, Law No. 468 of 1978 has pursued the goal of ensuring a stricter abidance to the rule of mandatory financial backing and has introduced the legislative tool of the Budget Law.

In abidance with this piece of legislation, some MEF-RGS administrative processes related to the Budget and the management of expenditure have been automated, the system for the creation and the management of the State Budget has been put into place in order to support the drafting of the Budget Law and the Central Budget Offices have drawn up procedures for the elaboration of the expenditure paperwork sent by Administrations.

\section{The Use of Innovative Tools: The Information Technology Mandate}

In 1994, with the adoption of Presidential Decree 367, began a new phase characterized by a marked change and innovation in the expenditure management administrative process. Information technology for the management of expenditure was introduced in order to substitute paperwork and to ensure verified information, efficient controls and speedy payments.

Furthermore, the liquidation of expenditure chapters was allowed through every accreditation or payment methods available in the banking and postal circuits.

The implementation of the Decree was achieved in 1999 by the introduction of the "Information Technology Mandate", an electronic expenditure order that, once digitally signed by MEF-RGS bureaus, is sent to the Bank of Italy through specific electronic channels, thus initiating a process of de-materialization of paperwork.

\section{The SIPA - Integrated System for Administrative Payments}

The creation and complete implementation of the Information Technology Mandate within all users (Central Budget Offices, General State Accounting Department, Bank of Italy), with its significant advantages in terms of payments effected, led to the decision to proceed with the extension of IT processes to the activity implemented by Central Administrations in the elaboration of their expenditure chapters and their delivery to the RGS.

The year 2000 witnesses the creation of the SIPA, Integrated System for Administrative Payments, an eGovernment project aimed at Public Administrations, citizens and enterprises.

The SIPA has as its main goal the substitution of paperwork with electronic documents in all that relates to variations in Budget chapters, to documents subject to legal verification on the part of the RGS, to documentation entailing a direct relation between expenditure managers and the Bank of Italy and to fixed expenditure chapters. 
The pursuit of these goals led to the following advantages for Administrations:

- The elimination of paperwork in dealings with RGS and Bank of Italy bureaus.

- The timely knowledge of the accounting situation of individual expenditure chapters.

- The availability of periodic accounting in automated form.

- The rationalization of processes related to the financial accounting of Administrations.

- The acceleration of payments through their integration with banking and postal services.

- The reduction of costs (both in terms of time and money) related to payment management.

In order to implement and manage the SIPA a dedicated Coordinating Committee was put into place bringing together the RGS, the Court of Audits, the Bank of Italy and the CNIPA, in order to:

- Elaborate programs aimed at promoting the participation of Administrations.

- Issue technical regulations on SIPA's infrastructure.

- Decide on requests to join the SIPA.

\section{The Spreading of Innovation: The Management Accounting System (SICOGE)}

The first step taken by the SIPA was the implementation of the connection of individual Administrations to the R.U.P.A (Public Administration Unitary Grid) and the interconnection between the networks of the R.U.P.A. and the R.N.I (National Inter-bank Grid), thus creating a data transmission system that guaranteed maximum security requirements on a par with those used by Italy's banks. This interconnection proved crucial to enable the digitalization of the expenditure management process of Administrations.

In 2001, MEF-RGS implemented the SICOGE (Financial Accounting Management Information System), totally integrating it with the RGS Information System (SIRGS). Through this system, every Administration could manage its budget and its complete expenditure process through the RUPA/RNI channel as a secure vehicle for data transmission to the RGS. This also allowed for the elimination of paperwork in the transmission of a significant amount of accounting documents. The process in fact currently involves 150,000 accreditation orders, 600,000 information technology mandates and 18 million IT operations regarding payments and pensions. Thus, the IT management of the administrative procedures of accounting activities allows to reach the following goals:

- Promoting the monitoring of Public Administration expenditure, improving the efficiency of the national system as a whole. 
- Accelerating payments through their integration with banking and postal services.

- Strengthening the IT capabilities of Administrations and allowing for the development of monitoring and decision-making support systems.

- Promoting the circulation of accounting information between all interested actors (Central Administrations, Local Authorities and Public Institutions).

- Communicating information to enterprises and State creditors regarding the administrative procedures of relevant activities, thus concretely contributing to improving the transparency of administrative activity.

- Simplifying expenditure management processes through the elimination from the administrative process of every step related to the production and transmission of accounting paperwork.

The use of SICOGE on the part of almost every single Administration brings significant benefits to administrative activity insofar as it:

- Allows for the certification of information and a greater speed in accounting operations.

- Promotes an easy integration between central and peripheral administrative offices.

- $\quad$ Allows the use of the digital signature and the elimination of paperwork

- Paves the way for an efficient management control and monitoring of expenditure.

- Optimizes, among other things, the operational costs of the State.

\section{The Evolution of the SICOGE}

In the meantime, the reform of the State Budget enacted with Law No. 94 of April 31997 and implemented with Legislative Decree No. 279 of August 7 1997 introduced Analytical Economic Accounting for the cost centers of Central State Administrations. This significant innovation in accounting standards highlighted the political will to create a budget for "parliamentary decision" and an "administrative-management" budget that would be interconnected and supported by efficient accounting tools capable of constantly informing the budget decision-making process. The Analytical Economic Accounting system for Central State Administrations aimed at the identification, analysis, verification and monitoring of costs, revenues and results of administrative activity allows for an economic qualification of public policies and of the final services that are provided, as well as for a verification of the way resources are employed, defined as an economic value of effective consumption, classified by their nature and allotted to the organization and goals pursued.

The new accounting model, its criteria and rules were defined by MEF-RGS and disseminated throughout all central Administrations. Furthermore, in order to 
facilitate the delivery of the economic budget documentation to be presented to Parliament, RGS made available to the Administrations a portal for the transmission of their pertinent data. Clearly, individual administrations would then needed a support system to manage all the information needed to draft an economic budget.

This naturally led to the integration of economic budget functions within the SICOGE, whose use had in the meantime been extended to all central administrations.

This system completely integrates economic-patrimonial-analytical data with financial data, thus allowing for monitoring of both the organization's real management costs and related expenses.

This way, every management action becomes visible through both its financial and economic aspects and can be evaluated in monetary terms. These are complementary aspects of the same reality, both significant in the evaluation of administrative activity and of the management performance of individual administration.

The development of this system for the integrated management of economic and financial accounting was conducted by RGS, through Consip, in accord with the CNIPA. It allows administrations to manage all the information they need to represent the use of resources in an economic, patrimonial and analytical way, to support their economic and financial planning activity and to feed in a homogenous, dependable and timely fashion the Analytical Economic Accounting system of Central State Administrations, as well as their own management control systems.

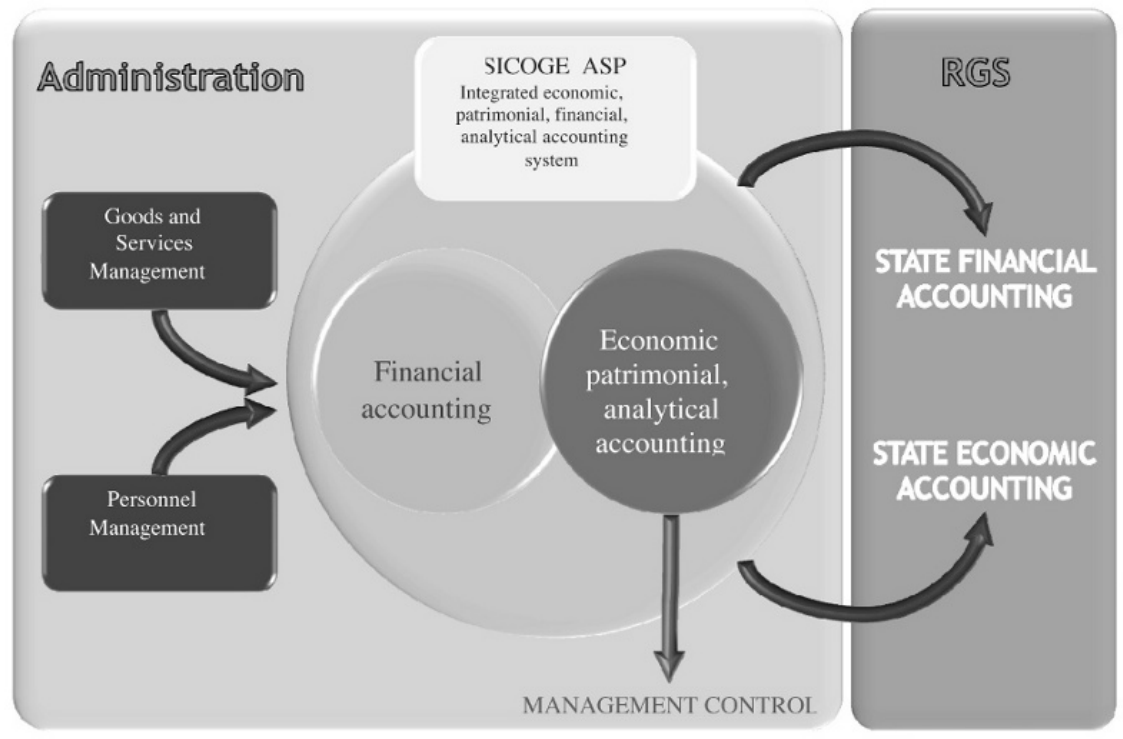


The ever more frequent use of the SICOGE on the part of all administrations, along with the technological evolution of the ICT market, have led RGS and CNIPA to sign an agreement in order to supply SICOGE in ASP (Application Service Provider) modality. This way, RGS acts as service provider, freeing administrations from activities related to the management, maintenance and upgrading of the infrastructure technology, which are delegated to the ASP manager (RGS).

The advantages that are provided through this delivery modality can be summarized in the following points:

? Rationalization of operational processes.

? Centralized management of the technical infrastructure.

? Greater back-office efficiency and total control of the service.

? Simplification of the system's functional and technical evolution.

? Central control of dialogue with other RGS information systems.

Furthermore, the centralized management of the service on the part of RGS allows administrations to use other services provided by RGS, foremost among them the substitutive conservation system which, in abidance with the legislative requirements dictated by the CNIPA, manages the entire conservation process (conservation, maintenance and search/visualization) in an open, scalable and integrated solution.

The ASP delivery, the digital signature and the substitutive conservation implemented through SICOGE allow the State to pursue the goals it has set for itself in terms of the de-materialization of all accounting flows, but -more importantly- they are the backbone of an extremely significant eGovernment project that integrates all central administrations into a single accounting system.

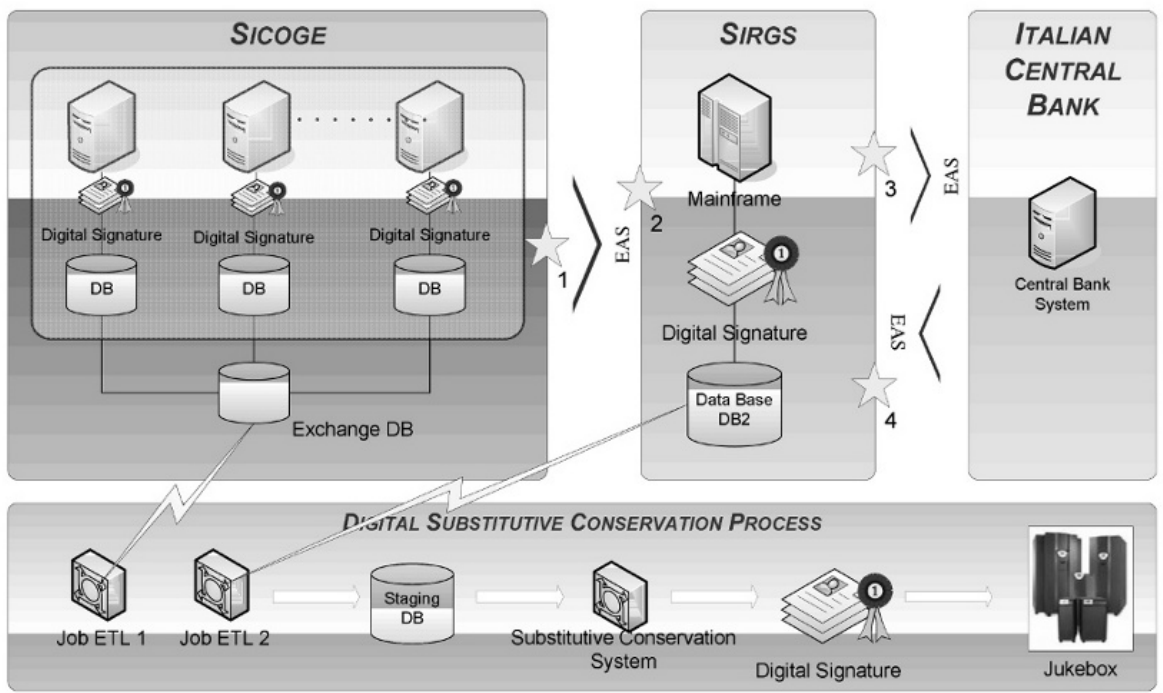

